\title{
A large abdominal intercostal hernia in a patient with vascular type Ehlers-Danlos syndrome: a surgical challenge
}

\author{
L. de Weerd $\cdot$ J. Kjæeve $\cdot$ L. Gurgia $\cdot$ \\ S. Weum
}

Received: 16 April 2010/Accepted: 16 August 2010/Published online: 17 September 2010

(C) The Author(s) 2010. This article is published with open access at Springerlink.com

\begin{abstract}
A patient with vascular type Ehlers-Danlos syndrome developed a large abdominal intercostal hernia secondary to coughing. The tissue friability and associated risks for arterial ruptures and visceral perforations in these patients make hernia repair challenging. The hernia was successfully treated using a novel approach.
\end{abstract}

Keywords Abdominal wall reconstruction - Abdominal intercostal hernia $\cdot$ Vacuum assisted closure system

\section{Introduction}

An abdominal intercostal hernia is a rarely reported condition. In their review of literature in 2007, Unlu et al. [1] registered only 29 cases in 23 publications. In 13 cases there was an abdominal intercostal hernia without a diaphragmatic abnormality; the other 16 cases were so-called transdiaphragmatic abdominal intercostal hernias $[1,2]$. Most

Presented at the Inaugural Conference on Abdominal Wall Reconstruction in Washington, DC, 25-27 June 2009, as oral and poster presentations.

L. de Weerd $(\bowtie) \cdot$ L. Gurgia

Department of Plastic Surgery and Hand Surgery,

University Hospital North Norway,

Sykehusveien 38, 9038 Troms $\emptyset$, Norway

e-mail: louis.deweerd@unn.no

J. Kjæve

Department of Gastrointestinal Surgery,

University Hospital North Norway, Troms $\emptyset$, Norway

S. Weum

Department of Radiology, University Hospital North Norway,

Troms $\varnothing$, Norway patients had a history of blunt or penetrating trauma. This case report describes a unique case of a patient with vascular type Ehlers-Danlos syndrome who developed a large abdominal intercostal hernia secondary to coughing. EhlersDanlos syndrome is a group of inherited connective tissue disorders characterised by the triad of skin hyperextensibility, joint laxity and tissue friability. Wound failure is a common feature and, classically, wound dehiscence occurs at 1 or 2 weeks after surgery [3]. The vascular type of Ehlers-Danlos syndrome is associated with life-threatening complications, including arterial rupture and visceral perforation [4-6]. We describe a novel approach to treat a large abdominal intercostal hernia in such a patient.

\section{Case report}

A 56-year-old female patient, previously diagnosed with vascular type Ehlers-Danlos syndrome, was referred to our hospital because of a large hernia in her left flank (Fig. 1a). According to the patient, a bulge had gradually developed over a 2-year period. Her history revealed no trauma but she recalled an episode with violent coughing followed by a sudden pain in her left flank. A few days later she noticed an area with bruising in her left flank followed by a swelling that enlarged progressively over time. The voluminous bulge caused marked discomfort to the patient, not only physically but also cosmetically. Examination revealed a large soft nontender bulge in the midaxillary line. Large veins were seen in the overlying subcutaneous tissue. The swelling increased on straining and coughing, but disappeared spontaneously with the patient in the opposite lateral posture. The 11th and 12th rib were identified as the cephalad and caudal border of the defect. There had been no signs of incarceration. A CT scan showed a herniation of abdominal viscera through a defect 
(a)

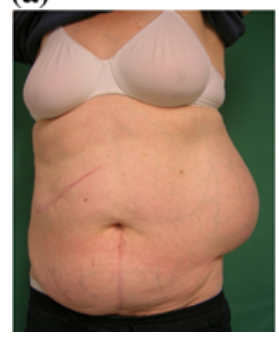

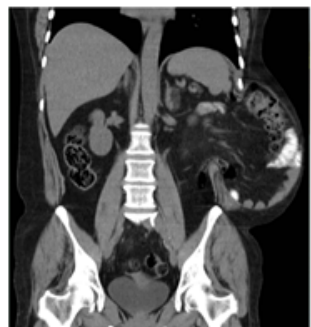

(b)

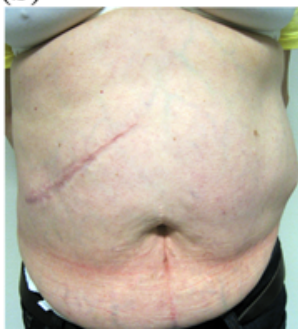

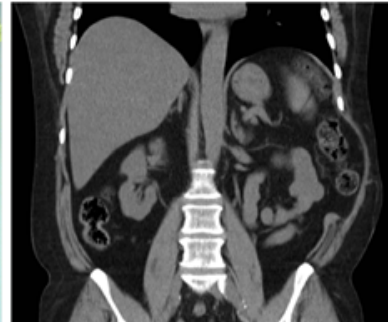

Fig. 1 a Preoperative view and CT scan of the abdominal intercostal hernia. b Postoperative view and CT scan at 2-year follow-up. The small bulge seen at follow-up had not increased in size since the operation

(a)

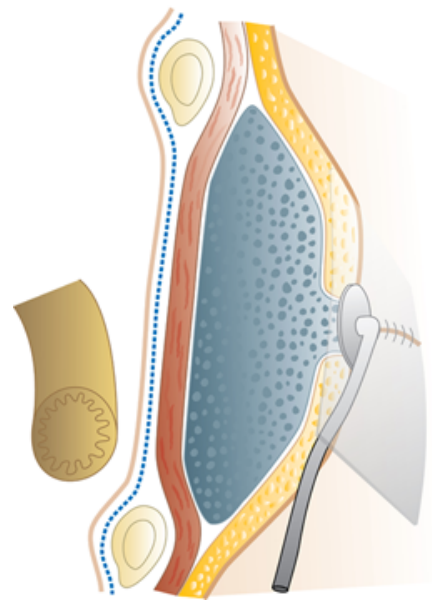

(b)

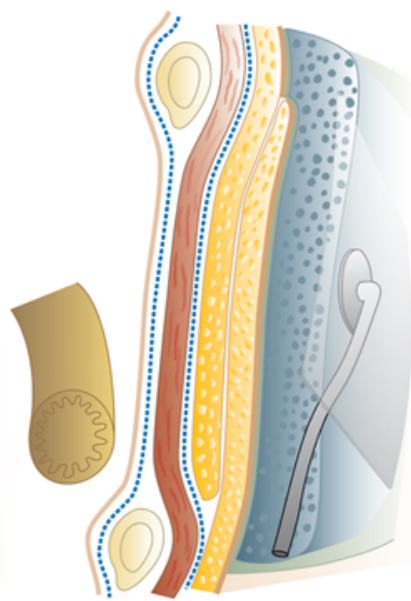

(c)

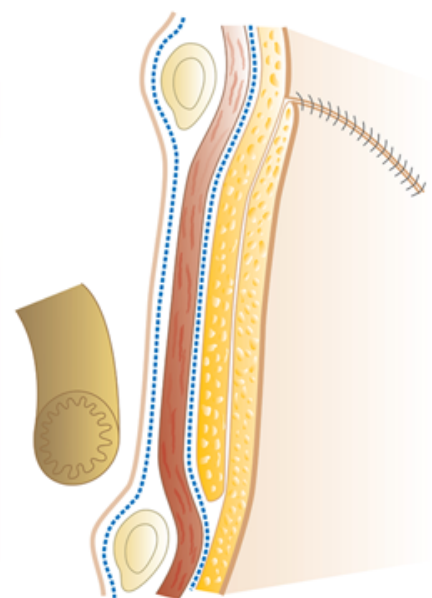

Fig. 2 a The mesh (dotted line) was positioned between peritoneum and muscle. Subcutaneous negative pressure stabilises the abdominal wall. b A second mesh positioned between the muscle and the double-breasted skin flaps stabilised by external negative pressure. $\mathbf{c}$ The end result

between the 11 th and 12 th rib that had a diameter of approximately $10 \mathrm{~cm}$. The hernia sac contained a large part of the descending colon. The spleen lay at the entrance of the sac (Fig. 1a).

\section{Operation}

With the patient in general anaesthesia and in the lateral posture, the skin and subcutaneous tissue were incised and the hernia sac was opened. Herniotomy was done at the neck of the hernia sac and the peritoneum was closed with absorbable sutures. A polypropylene mesh was positioned over the peritoneum and sutured to the periosteum of the 11th and 12 th rib with non-absorbable monofilament sutures. The latissimus dorsi and external oblique muscles were approximated to provide muscle coverage over the mesh. A polyurethane sponge of a negative pressure device [Vacuum Assisted Closure (VAC) system, KCI Medical, Arizona, TX] was positioned over the muscle. To reduce the risk of bleeding when changing the sponge, it was wrapped in a thin semipermeable polyamide sheet (Surfasoft, Mediprof,
Moerkapelle, The Netherlands). The VAC system was set at a continuous $125 \mathrm{mmHg}$ subatmospheric pressure. Every 3-4 days the sponge was changed, the first time in general anesthesia, later in local anesthesia. The patient was mobilised from the second postoperative day. After 3 weeks the patient was reoperated. The sponge was removed and a second polypropylene mesh was positioned over the muscle layer. After deepithelialisation, the expanded skin was double-breasted to provide adequate coverage over the mesh (Fig. 2). After skin closure, the skin was covered with a large semiadhesive hydrocolloid dressing (Duoderm, ConvaTec, Lakewood, NJ). The wound was stabilised by applying the VAC system directly to the Duoderm plate for 1 week. The patient used a hernia belt for an additional period of 3 months. The postoperative course was uneventful. At 2-year follow-up there were no signs of recurrence (Fig. 1b).

\section{Discussion}

No reports were found on an abdominal intercostal hernia in a patient with vascular type Ehlers-Danlos syndrome. 
Hernia repair in such a patient is a surgical challenge, due not only to the characteristic tissue friability, but also to the associated life-threatening complications, including arterial ruptures and bowel perforations [3-7]. According to DiBello and Moore [8], the ideal abdominal wall reconstruction should fulfill the following criteria: (1) prevent visceral eventration, (2) provide a tension-free repair, (3) incorporate with the remaining abdominal wall, (4) provide dynamic muscle support, and (5) endure over time.

The open approach provided an excellent overview and allowed for delicate tissue handling. Although a laparoscopic approach has been reported for the treatment of an abdominal intercostal hernia, the risk of arterial ruptures and visceral perforations was considered too high in this patient [2, 7, 9]. Closure of the intercostal defect by approximating the separated ribs is seen as a critical step in the repair of an abdominal intercostal hernia as it prevents visceral eventration [10]. However, due to muscle contraction, the 12 th rib was retracted caudally and could not be mobilized without performing an extensive dissection. This would have weakened the abdominal wall caudally to the 12 th rib and would have increased the risk of hernia in that area. Primary closure of this large defect would lead to local tissue ischemia and would have increased the risk of hernia recurrence. The use of a mesh allowed for a tensionfree closure of the defect. Interposing peritoneum between the mesh and bowels is reported to reduce the risk of meshrelated problems such as infection and fistula formation [2, 11]. The retromuscular position of the mesh provides a physiological fixation of the mesh at the onset of increased intra-abdominal pressure. This technique is used widely for open mesh repair and with good results since its description by Rives in 1973 [12] and later by Stoppa [13].

The VAC system is used widely in wound treatment. In this case report, a novel indication of the VAC system was introduced. Wound dehiscence is a common problem in Ehlers-Danlos patients due to the collagen disorder. Hernia repair in these patients is therefore very challenging. In this case report a mesh was positioned under a muscle layer. Ingrowth of tissue into the mesh is optimised with immobilisation of the affected area. In this patient, the VAC sponge was positioned over the muscle layer, stabilising the suture line between the obliquus externus and latissimus dorsi muscles as well as the abdominal wall. Patients with the vascular type of Ehlers-Danlos syndrome are characterised by spontaneous vessel ruptures and therefore bleed easily. In our patient, the episode of coughing caused most likely a disruption of the intercostal muscles and bleeding and subsequently the intercostal hernia. Disruption of the mesh from the muscle could lead to bleeding and recurrence of the hernia. Temporary stabilisation of the abdominal wall using the VAC system may prevent such complications.
Although a single mesh might have been sufficient, tissue friability and hyper-elasticity in this patient were risk factors for recurrence. We used a second mesh to provide additional stability to the abdominal wall; again this time we used the VAC system for postoperative stabilisation. Although one might speculate whether the second mesh could have been positioned initially, it was important that enough fibrosis developed in the area where the hernia had occurred. Due to the collagen disorder, it is likely that the formation of fibrosis would take a longer time than usual. The additional fibrosis induced by the second mesh may further reduce the incidence of wound failure and hernia recurrence $[2,10]$.

At 2-year follow-up there were no clinical or radiological signs of hernia recurrence. The small bulge that the patient had directly after the operation had not increased in size, indicating that a stable reconstruction was obtained. With our approach, four of the five criteria set by DiBello and Moore [8] are fulfilled; however, the criterion of dynamic muscle support is not fulfilled. Dynamic muscle support is important for the reconstruction of the anterior abdominal wall. In contrast, for closure of the intercostal space it might be preferable to have a more rigid reconstruction, especially in a patient that suffers from tissue friability.

The approach described in this case report may also be well suited for other complex abdominal wall reconstructions. The temporary use of a negative pressure system helps to stabilise the abdominal wall until the mesh or autologous tissue is incorporated into the abdominal wall.

Open Access This article is distributed under the terms of the Creative Commons Attribution Noncommercial License which permits any noncommercial use, distribution, and reproduction in any medium, provided the original author(s) and source are credited.

\section{References}

1. Unlu E, Temizoz O, Cagli B (2007) Acquired spontaneous intercostal abdominal hernia: case report and a comprehensive review of the world literature. Australas Radiol 51:163-167

2. Bobbio A, Ampollini L, Prinzi G, Sarli L (2008) Endoscopic repair of an abdominal intercostal hernia. Surg Laparosc Endosc Percutan Tech 18:523-525

3. Girotto JA, Malaisrie SC, Bulkely G, Manson PN (2000) Recurrent ventral herniation in Ehlers-Danlos syndrome. Plast Reconstr Surg 106:1520-1526

4. Beighton PH, Murdoch JL, Votteler T (1969) Gastrointestinal complications of the Ehlers-Danlos syndrome. Gut 10:1004-1008

5. Bläker H, Funke B, Hausser I, Hackert T, Schirmacher P, Autschbach F (2007) Pathology of the large intestine in patients with vascular type Ehlers-Danlos syndrome. Virchows Arch 450:713-717

6. Privitera A, Milkhu C, Datta V, Sayegh M, Cohen R, Windsor A (2009) Spontaneous rupture of the spleen in Type IV EhlersDanlos syndrome: report of a case. Surg Today 39:52-54 
7. Baichi MM, Arifuddin RM, Mantry PS (2005) Gastrointestinal bleeding in a patient with Ehlers-Danlos syndrome: an endoscopic dilemma. Dig Dis Sci 50:1342-1343

8. DiBello JN, Moore JH (1996) Sliding myofascial flap of the rectus abdominis muscle for the closure of recurrent ventral hernias. Plast Reconstr Surg 98:464-469

9. Kurer MA, Badford IMJ (2006) Laparoscopic repair of abdominal intercostal hernia: a case report and review of the literature. Surg Laparosc Endosc Percutan Tech 16:270-271

10. Best IM (2001) Complication of the retroperitoneal approach: intercostal abdominal hernia. Am Surg 67:635-636
11. Luijendijk RW, Hop WC, van den Tol MP, de Lange DC, Braaksma MM, IJzermans JN, Boelhouwer RU, de Vries BC, Salu MK, Wereldsma JC, Bruijninckx CM, Jeekel J (2000) A comparison of suture repair with mesh repair for incisional hernia. N Engl J Med 343:392-398

12. Rives J, Lardennois B, Pire JC, Hibon J (1973) Les grandes eventrations:importance du 'volet abdominal' et des troubles respiratoires qui lui sont sécondaires. Chirurgie 99:547-563

13. Rosch R, Junge K, Conze J, Krones CJ, Klinge U, Schumpelick V (2006) Incisional intercostal hernia after a nephrectomy. Hernia 10:97-99 